\title{
The impact of the development of negative soil processes on the land fund of the Russian Federation
}

\author{
Eleonora Tsoraeva ${ }^{1, *}$, Larisa Basieva $^{2}$, and Batrbek Kozyrev ${ }^{3}$ \\ 1 I.T. Trubilin Kuban State Agrarian University, 350044, 13, Kalinina str., Krasnodar, \\ Russian Federation \\ ${ }^{2}$ Gorsky State Agrarian University, 362040, 37, Kirova str., Vladikavkaz, Russian Federation \\ ${ }^{3}$ Saint-Petersburg State University of aerospace instrumentation, 190000, 67, Bolshaya Morskaya, \\ Saint-Petersburg, Russian Federation
}

\begin{abstract}
One of the reasons of the reduction of agricultural land is the degradation of soil processes. The main negative processes occurring in soils and leading to their degradation are erosion (water and wind), reduction of humus content in the soil. A significant spread of negative processes developing due to the action of natural and anthropogenic factors leads to a critical decrease in soil fertility. By washing away the upper fertile soil layer and the formation of large gullies due to improper tillage, soil erosion is formed. In order to prevent soil erosion, it is necessary to take measures to prevent an increase in the area of degraded land. The article considers the impact of negative processes, such as water and wind erosion, salinization, overwetting, flooding and waterlogging of soils, etc. on the land fund.
\end{abstract}

\section{Introduction}

Rational and efficient use of main means of agricultural production - agricultural land is an important factor in ensuring food security of the Russian Federation. According to the Doctrine of Food Security of the Russian Federation, one of the main provisions of the National Security Strategy of the Russian Federation, the national interests of the state is to restore and increase the fertility of agricultural land, prevent the reduction of agricultural land areas, rational use of such land, protect and preserve agricultural land from water and wind erosion and desertification [1].

However, the Doctrine reflects the risks that a country may face when implementing it. One of them is an increase in the share of degraded land and a decrease in the fertility of agricultural land due to their irrational use in agriculture. In this regard, one of the main directions of the state policy in the field of ensuring food security is the restoration and improvement of the fertility of agricultural land, rational use of agricultural land, compliance with crop production technologies, as well as the development of agricultural

\footnotetext{
* Corresponding author: elionora@list.ru
} 
land reclamation by maintaining a reclamation complex which is owned by the Russian Federation.

\section{Methods}

The materials for the study were statistical data of the Department of the Federal Service for State Registration, Cadastre and Cartography for the Krasnodar Territory (Report on the use and state of land in the Krasnodar Territory for 2005, 2010, 2015, 2019, as well as the Report on the availability of land and their distribution by categories, lands and forms of ownership in the Krasnodar Territory for 2005, 2010, 2015, 2019). Methods of statistical and system analysis were used to accomplish the assigned tasks.

\section{Results}

In order to timely identify and prevent the development of negative processes, as well as the rational increase of agricultural production on agricultural lands, federal state budgetary institutions subordinate to the Ministry of Agriculture of the Russian Federation conduct state monitoring of agricultural lands, including agro-soil monitoring [3].

In 2019, the area of agricultural land was studied for negative processes amounted to 12,773. 25 thousand hectares (in 2018 - 13,822. 14 thousand hectares, in 2017-10485.45 thousand hectares). Of these, agricultural lands subject to wind erosion amounted to 1643.74 thousand hectares ( $12.9 \%$ of the studied area), subject to water erosion-2467.89 thousand hectares $(19.3 \%$ of the studied area), salinization -277.51 thousand hectares ( $2.2 \%$ of the studied area), waterlogging-849.76 thousand hectares $(6.7 \%$ of the studied area) $[9,10]$. Table 1 shows the results of researches conducted in 2013-2019.

Table 1. The spread of negative processes in studied territories of the Russian Federation in $2013-2019$ th/ha $[1,2]$.

\begin{tabular}{|c|c|c|c|c|c|c|c|c|c|}
\hline \multirow{2}{*}{ Year } & \multirow{2}{*}{ Studied, th/ha } & \multicolumn{2}{|c|}{$\begin{array}{c}\text { Wind } \\
\text { erosion }\end{array}$} & \multicolumn{2}{|c|}{ Wind erosion } & \multicolumn{2}{|c|}{ Salinization } & \multicolumn{2}{|c|}{ Overwetting } \\
\hline & & th/ha & $\%$ & th/ha & $\%$ & th/ha & $\%$ & th/ha & $\%$ \\
\hline 2013 & 8879,43 & 1162 & 13 & 1357,73 & 15 & 248,49 & 3 & 490,2 & 5 \\
\hline 2014 & $\begin{array}{l}4233,88- \\
6673,42 * \\
\end{array}$ & 1403,35 & 21 & 151251,51 & 24,2 & 108,89 & 2,6 & 234,45 & 4,4 \\
\hline 2015 & $\begin{array}{l}2869,64- \\
3750,64 *\end{array}$ & 551,93 & 18,9 & 591,31 & 15,8 & 101,48 & 3,5 & 149,25 & 4,3 \\
\hline 2016 & $\begin{array}{l}4233,88- \\
6673,42 * \\
\end{array}$ & 1403,35 & 21,1 & 1512,51 & 24,2 & 108,88 & 2,6 & 234,45 & 4,4 \\
\hline 2017 & 10485,45 & 1427,17 & 13,6 & 1847,17 & 17,6 & 432,58 & 4,1 & 763,78 & 7,3 \\
\hline 2018 & 13822,14 & 1252,79 & 9,1 & 2048,08 & 14,8 & 241,53 & 1,7 & 722,51 & 5,2 \\
\hline 2019 & 12773,25 & 1643,74 & 12,9 & 2467,89 & 19,3 & 277,51 & 2,2 & 849,76 & 6,7 \\
\hline
\end{tabular}

${ }^{*}$ Depending on the type of negative process

According to the results of observations, soil erosion is one of the main factors hindering the increase in crop yields. The largest areas of arable land subject to wind and water erosion are located in Volga Federal District, the smallest ones -in Ural Federal District (Table 2).

Wind erosion (deflation) takes out the smallest soil particles and manifests itself on all types of terrain. According to the degree of manifestation of deflation in accordance with the loss of humus horizon, the following soils are distinguished: - weakly ventilated - a 
decrease in the humus layer by up to $20 \%$; - medium - ventilated - a decrease in the humus layer by $21-40 \%$; - highly ventilated - a decrease in the humus layer by $41-60 \%[9,10]$.

In 2019, the main share of eroded soils was made up of poorly ventilated soils with an area of 1309.69 thousand hectares, or $79.7 \%$ of the total area of the studied agricultural land subject to wind erosion (deflation). Medium-leached soils occupied 233.13 thousand hectares (14.2\%), highly - leached-100.91 thousand hectares $(6.1 \%)$.

Water erosion is the process of destruction of the soil cover under the influence of thawed, rain or irrigation water, which at the same time contributes to the occurrence of soil drought due to the runoff of a significant part of precipitation from the slopes, as well as siltation of rivers and reservoirs by the washed-off soil layer. Depending on the intensity of the annual erosion, the degree of soil erosion is divided into the following categories:

- slightly washed - the intensity of the annual flushing of the fertile soil layer is 0.5 $1.0 \mathrm{t} / \mathrm{ha}$;

- medium- washed - 1.0-5.0 t/ ha;

- heavily washed $-5.0-10.0 \mathrm{t} / \mathrm{ha}$.

In 2019 , the area of lightly washed soils amounted to 2046.20 th/ha $(82.9 \%$ of the identified area of agricultural land subject to water erosion), medium-washed - $352.91 \mathrm{th} / \mathrm{ha}$ $(14.3 \%)$, heavily washed -68.79 th/ha $(2.8 \%)$.

Erosion processes in the form of water and wind erosion on all agricultural lands have a significant negative impact on the ecological and economic situation of each economic entity, significantly reduce soil fertility, which certainly requires comprehensive measures to protect land resources from the effects of water and wind erosion. Nowadays, there are many modern innovative methods of soil erosion control. All these measures should be developed in the process of drawing up master plans for the use of the land area, land management projects and intensive land management, as well as various projects for the protection of both land resources and the overall natural environment of a particular region or specific territory $[9,10]$.

Salinization is the process of excessive accumulation of water-soluble salts in soils in quantities harmful to plants. Anthropogenic activity can increase soil salinization. According to the degree of salinity of the soil are divided into: - slightly saline - the content of water-soluble salts $0.25-0.4 \%$;

- medium- saline - 0.4-0.7\%;

- highly saline - $0.7-1.0 \%$;

- very highly saline (salt marshes) - more than $1 \%$.

According to the results of the 2019 research, slightly saline soils remain the most common - 161.37 thousand hectares, which is $58.1 \%$ of the identified saline soil area. Medium-saline soils occupy an area of 74.38 thousand hectares $(26.8 \%)$, highly saline 29.09 thousand hectares $(10.5 \%)$, salt marshes - 12.66 thousand hectares $(4.6 \%)$.

Overwetting. Waterlogged soils are those formed under conditions of excessive moisture compared to normal for this natural zone. Excessive moisture is a condition of the soil when the average moisture content in it exceeds $70-80 \%$ of the total moisture capacity during the growing season. Waterlogged soils are divided into following categories:

- floodplain;

- out - of - floodplain,

- waterlogged.

Floodplain soils are common in all zones and each of them has its own characteristics. There are many swamp floodplain soils in the taiga-forest zone and saline floodplain soils in the semi-desert and desert zones. Swampy soils are soils with excessive humidity during most of the growing season. 
In 2019, floodplain soils occupied 175.74 th/ha, or $20.68 \%$ of the total area of soils subject to waterlogging, out-of-floodplain soils - 537.48 th/ha (63.25\%), swampy - 136.54 th/ha $(16.07 \%)$.

Waterlogging is the process of formation of swamps on waterlogged areas of the earth's surface (OST 23. 001-96). Waterlogging leads to a strong gluing of the entire soil profile, accumulation of nitrous forms of iron, manganese and some other elements in it including products of anaerobic decomposition of organic substances that are harmful to most plants.

Flooding is the rise of the groundwater level to the daytime surface caused by natural or anthropogenic factors and leading to water saturation of soils, changes in the physical and physical-chemical properties of groundwater, transformation of soils, species composition, structure and productivity of vegetation cover, transformation of animal habitats (OST 23. 001-96). Flooded lands are the lands that have been flooded as a result of economic activity (OST 23. 001-96).

To the greatest extent, the processes of overwetting and waterlogging are manifested on the territory of the Central (more than $30 \%$ of all wetlands in Russia) and Siberian (more than $20 \%$ ) federal districts. To a large extent, waterlogging is typical for regions located in the humid zone, such as Tver (28.9\% of the wetlands of the district), Moscow (12.3\%) and Smolensk (10.9\%) zones. Waterlogging is widespread in Novosibirsk $(19.4 \%$ of the wetlands of the district) and Tomsk (15.2\%) regions, Altai Territory (17.1\%), Omsk Region $(12.3 \%)$ and the Republic of Buryatia $(6.5 \%)$. The tendency to increase the areas of waterlogged and wetlands, mainly due to the influence of the anthropogenic factor, is observed in the south of the European part of the country.

Land flooding is the covering of the territory with water, which occurs due to an increase in the level surface of a water body or groundwater, as well as due to the accumulation of precipitation in the depressions of the terrain and during irrigation by flooding (OST 23. 001-96).

The violation of land is understood as a process that occurs during the extraction of minerals, the performance of geological exploration, survey, construction and other works and leads to a violation of the soil cover, hydrological regime of the area, formation of man-made relief and other qualitative changes in the state of the land (GOST 17.5.1.01-83). The disturbed lands include quarries of mineral raw materials formed as a result of mining, dumps of soil, land, pollution by waste from industrial enterprises, disturbed during industrial forest management, etc $[10,11]$.

A significant spread of negative processes - water and wind erosion, salinization, overwetting, flooding and waterlogging of soils, developing due to the action of natural and anthropogenic factors, leads to a critical decrease in fertility and, consequently, to the retirement of land from agricultural circulation $[4,8]$. The development of the processes of soil degradation in combination with the lack of financial, labor and technical resources of agricultural producers to preserve and replenish soil fertility, as well as to maintain land plots in a usable condition, leads to their retirement from agricultural turnover. The practice of transferring land shares to short-term leases also does not contribute to the reduction of unused land, since this approach does not encourage the tenant to carry out anti-erosion measures and maintain soil fertility. 


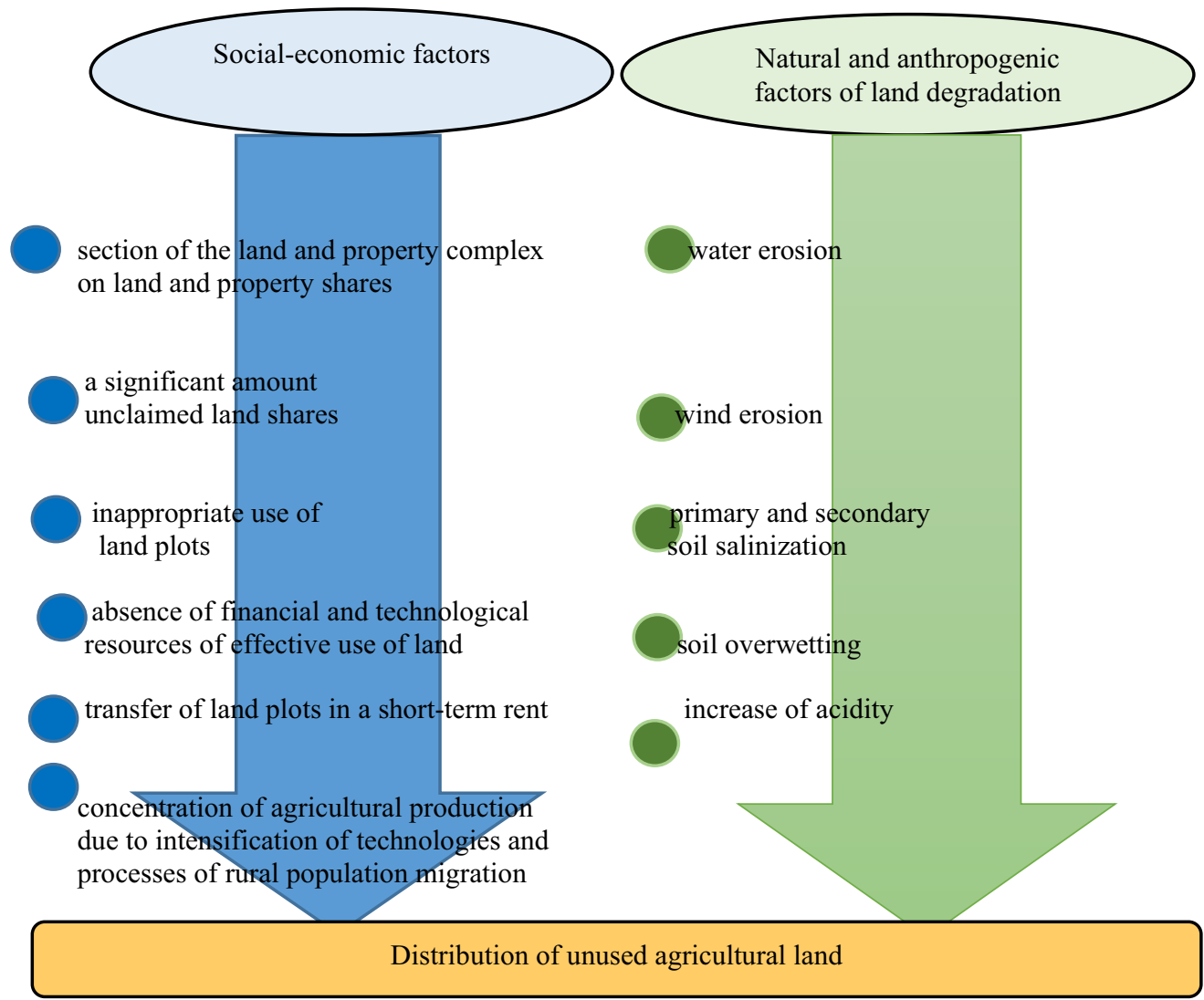

Fig. 2. Factors affecting the distribution of unused agricultural land of the Russian Federation.

The use of satellite imagery materials from domestic spacecraft and open data from foreign satellites allows us to solve a number of agricultural tasks on a large scale and quickly, such as inventory of agricultural land and crop rotation control. A significant area of land becomes unsuitable for cultivation and use in agricultural production due to the overgrowth of the land with woody and shrubby vegetation. The use of up-to-date remote sensing data of high spatial resolution in comparison with ground-based field surveys makes it possible to determine the negative processes leading to the unsuitability of land with greater efficiency and scale. In 2018, the problem of overgrowth of land was very relevant for many subjects of the Russian Federation, especially for the central part of Russia and the northern regions [5].

1. Precision farming is an organization of agricultural management. It is based on the idea of unevenness in the fields. It provides for the use of GPS systems, variable rate production, crop estimation, remote sensing of the land, geographic information systems. The program reduces the negative impact on the external environment. The efficiency and productivity of the agricultural sector is improving.

2. Organic agriculture helps to reduce the negative consequences of environmental management. It is based on the concept of health, justice, ecology and care. The goal is to improve the condition of animals, people, soil.

3. Conservation agriculture protects against destruction. The key point in the operation of the system is grain-fallow crop rotations. The system is used in arid regions, it provides a high yield of products. 
4. The way of chemicalization of agriculture provides for the harmless use of chemicals for the following tasks: improving the condition of the crop; increasing animal production; beneficial effect on soil condition; protection of crops from bacteria and insects.

\section{Discussion}

The development and spread of negative processes on agricultural land of the Russian Federation remains one of the main sources of loss of resource potential of soil fertility and reduction of crop yields, deterioration and pollution of ecological environment. One of the reasons for the decline in agricultural land is soil degradation processes. The main negative processes occurring in soils and leading to their degradation are erosion (water and wind) and a decrease in the humus content in the soil. A significant spread of negative processes developing as a result of the action of natural and anthropogenic factors leads to a critical decrease in soil fertility. The washout of the upper fertile soil layer and the formation of large gullies due to improper soil treatment results in soil erosion.

Negative processes include water and wind erosion, salinization, overwetting, flooding and waterlogging of soils, etc., developing due to the action of natural and anthropogenic factors, which leads to a decrease in soil fertility [2]. Degraded soils cease to perform natural and economic functions and can change natural and climatic conditions, which in turn leads to a decrease in the efficiency of land management and agricultural production in general (including the disposal of land plots from agricultural turnover) (Figure 1, Table 1).

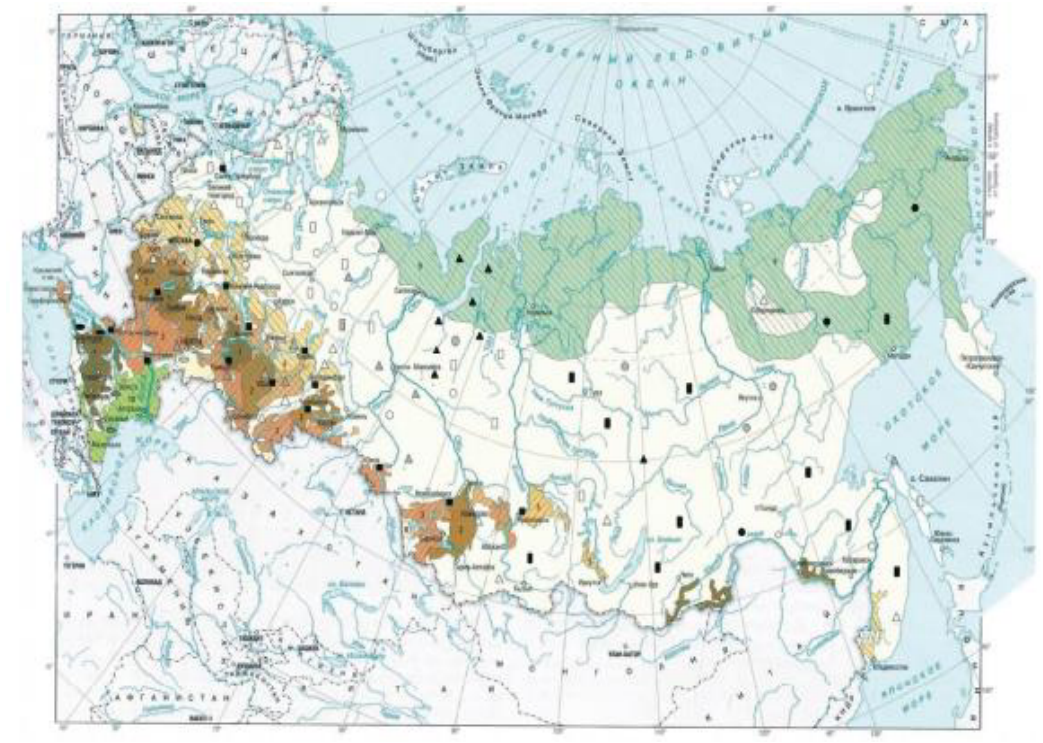

Fig. 1. The spread of soil degradation in the Russian Federation.

\section{Conclusion}

The systematic monitoring of land is necessary to identify negative processes. It will prevent the consequences of these processes, as a result of timely adoption of the necessary measures. The soil cover is a natural base for human living. It allows us to create an optimal ecological environment for life, work and recreation of people [6]. The purity and composition of the atmosphere, ground and underground waters depend on the nature of the soil cover, soil properties, chemical and biochemical processes occurring in the soil. The 
soil cover is one of the most powerful regulators of the chemical composition of the atmosphere and hydrosphere. The soil was and remains the main condition for life support of nations and humanity as a whole [7].

The preservation and improvement of the soil cover, and, consequently, the main vital resources in the conditions of intensification of agricultural production, industrial development, rapid growth of cities and transport are possible only with well-established control over the use of all types of soil and land resources.

\section{References}

1. Decree of the President of the Russian Federation «On the approval of the Doctrine of the Food Security of the Russian Federation» (2020)

2. E.N Tsoraeva, A.A. Bekmurzov, S.G. Kozyrev, A.H. Khoziev, A.Kh.Kozyrev, Environmental issues of agriculture as a consequence of the intensification of the development of agricultural industry E3S Web of Conferences, 215 (2020)

3. E.N Tsoraeva, S.A. Mezhyan, M.V. Kataeva, L.M. Hugaeva, T.A. Rogova, GIS technologies used in zoning agricultural land for optimizing regional land use E3S Web of Conferences, 224 (2020)

4. B.A. Kozyrev, E.N. Tsoraeva, Al-Azawi Nagam, A.A. Chibirova, A.Kh. Kozyrev, Rational use of land resources: regional aspect E3S Web of Conferences, 244 (2021)

5. S.A. Bekuzarova, S.S. Basiev, A.Kh. Kozyrev, T.A. Dulaev, V.I. Buyankin, Journal of Pharmaceutical Sciences and Research., 10, 4 (2018)

6. E.N. Stratinskaya, Scientific journal of the Russian Research Institute of Melioration Problems, 7, 1 (2011)

7. E.N. Tsoraeva, Results of research work for 2017, a collection of articles based on the materials of the 73rd scientific and practical conference of teachers (2018)

8. V.D. Zhukov, E.N. Tsoraeva, A.U. Perov, Problems of land use of water protection zones IOP Conf. Series: Earth and Environmental Science, 650 (2021)

9. P. Tsymbarovich. G. Kust, M. Kumani, V. Golosov, O. Andreeva, Russia International Soil and Water Conservation Research, 8 (2020)

10. M. Biddoccu, G. Guzman, G. Capello, T. Thielke, P. Strauss, S. Winter, J.G. Zaller, A. Nicolai, D. Cluzeau, D. Popescu, C. Bunea, A. Hoble, E. Cavallo, J.A. Gomez, Evaluation of soil erosion risk and identification of soil cover and management factor (C) for RUSLE in European vineyards with different soil management International Soil and Water Conservation Research, 8 (2020) 